\section{SÍNTOMAS CRÓNICOS TRAS EPISODIO DE DENGUE, UNA NECESIDAD DE INVESTIGACIÓN}

\author{
CHRONIC SYMPTOMS AFTER A DENGUE \\ EPISODE, A NEED FOR RESEARCH
}

\author{
Fernando Choque-Chávez ${ }^{1, a}$, \\ Francisco Huamaní-Fuente ${ }^{1, a}$, Carlos Canelo-Aybar ${ }^{1, b}$
}

Sr. Editor. El dengue es una de las enfermedades virales metaxénicas reemergentes con mayor carga de enfermedad y socioeconómica en regiones tropicales y subtropicales. Se estima que más de la mitad de la población mundial vive en áreas de riesgo. En América Latina, casi todos los países son endémicos o hiperendémicos, excepto, Chile y Uruguay. El Perú reportó, en el período 2004-2010, 9917 casos de dengue; ubicándose en la decimoctava posición de los países que más casos reportaron ${ }^{(1)}$. Desde el año 1990 hasta el 2014, el país ha evidenciado una tendencia al incremento en el número de casos de dengue, especialmente en los departamentos de la Amazonía y la costa norte. Durante el 2015 los casos reportados hasta la semana epidemiológica 20, llego a 20536 $(41,6 \%$ confirmados y $58,4 \%$ probables $)$ y un total de 20 muertes confirmadas ${ }^{(2)}$.

La infección por virus del dengue tiene un amplio espectro de manifestaciones clínicas, ya que se pueden presentar desde síntomas inespecíficos hasta fenómenos hemorrágicos graves, choque hemodinámico y falla multiorgánica ${ }^{(1)}$. La sintomatología aguda más común de la enfermedad se presenta con fiebre, cefalea, dolor retroorbitario, fatiga, mialgia, artralgia, anorexia, sabor metálico en la boca, vómitos, diarrea, dolor abdominal, erupción cutánea, hemorragias, entre otros.

Existe evidencia de que el dengue puede presentar sintomatología crónica después de que la fase aguda se haya autolimitado. García et al. reportaron que $56,7 \%$ de pacientes, que padecieron dengue clínico en La Habana en el 2006, presentaron sintomatología de la enfermedad dos años después de haber sido infectados (3). La mayoría de manifestaciones de esta fase crónica de la enfermedad son similares a la de la fase aguda y las dos más comunes fueron mialgias $(30,2 \%)$ y artralgias $(29,5 \%)$. Sin embargo, se reportaron síntomas que no se presentan comúnmente en la etapa aguda; por ejemplo, pérdida de la memoria en un $19,4 \%$ de los casos ${ }^{(4)}$. Por otro lado, Seet et al. encontraron que el $25 \%$ de pacientes hospitalizados con infección por dengue presentaron síndrome de fatiga posinfecciosa; asociados con el sexo femenino, la presencia de escalofríos y la ausencia de erupción en la etapa aguda ${ }^{(3)}$. Así mismo, Gonzáles et al. reportaron como síntomas notificados después de los seis meses de la infección aguda fueron astenia $(27,6 \%)$, cefalea $(14,8 \%)$ y artralgia $(10,6 \%)$ en un total de 47 pacientes estudiados ${ }^{(5)}$.

El impacto socioeconómico del dengue es importante, en las Américas durante el período 2000-2007 ocasionó un costo de USD 2,1 billones; y el número estimado de DALY perdidos por año fue de 45080 a $115874^{\left({ }^{(6)}\right.}$. De este cálculo, el $72,9 \%$ pertenecen a casos ambulatorios (fase aguda) de la enfermedad. En este sentido, recomendamos realizar una mayor cantidad de investigaciones acerca de la sintomatología crónica que se puede presentar en el dengue, ya que de esta forma se puede obtener una evaluación de la enfermedad a largo plazo y determinar el impacto real que esta provoca en la sociedad.

Contribuciones de los autores: Fernando Choque-Chávez, Francisco Huamaní-Fuente y Carlos Canelo-Aybar han participado en la concepción y diseño del artículo, redacción del artículo, revisión crítica del artículo, aprobación de su versión final y obtención del financiamiento. Carlos Canelo Aybar, además, ha participado en la asesoría técnica.

Fuentes de financiamiento: autofinanciado.

Conflictos de interés: los autores no declaran conflictos de interés.

\footnotetext{
Escuela de Medicina, Universidad Peruana de Ciencias Aplicadas. Lima, Perú.

astudiante de Medicina; ${ }^{\mathrm{b}}$ médico internista, epidemiólogo

Recibido: 29-10-15 Aprobado: 04-11-15
} 


\section{REFERENCIAS BIBLIOGRÁFICAS}

1. World Health Organization. Global Strategy for dengue prevention and control, 2012-2020. Geneva: WHO; 2012. Disponible en: http://apps.who.int/iris/ bitstream/10665/75303/1/9789241504034_eng.pdf

2. Ministerio de Salud. Bol Epidemiol (Lima). 2015; 24(21)

3. García G, González N, Pérez AB, Sierra B, Aguirre E, Rizo D, et al. Long-term persistence of clinical symptoms in dengueinfected persons and its association with immunological disorders. Int J Infect Dis. 201 1;15(1):e38-43. doi: 10.1016/j. ijid.2010.09.008.

4. Yeo PS, Pinheiro L, Tong P, Lim PL, Sitoh YY. Hippocampal involvement in dengue fever. Singapore Med J. 2005 Nov;46(11):647-50.
5. Gonzáles D, Martínez R, Castro O, Serrano T, Portela D, Vasquez S, et al. Evaluation of Some Clinical, Humoral and Imagenological Parameters in Patients of Dengue Haemorrhagic Fever Six Months after Acute Illness. Dengue Bulletin. 2005;29:79-84.

6. Shepard DS, Coudeville L, Halasa YA, Zambrano B, Dayan GH. Economic Impact of Dengue Illness in the Americas. Am J Trop Med Hyg. 2011;84(2):200-7. doi: 10.4269/ ajtmh.2011.10-0503.

Correspondencia: Carlos Canelo-Aybar

Correo electrónico carlos.canelo.ay@gmail.com

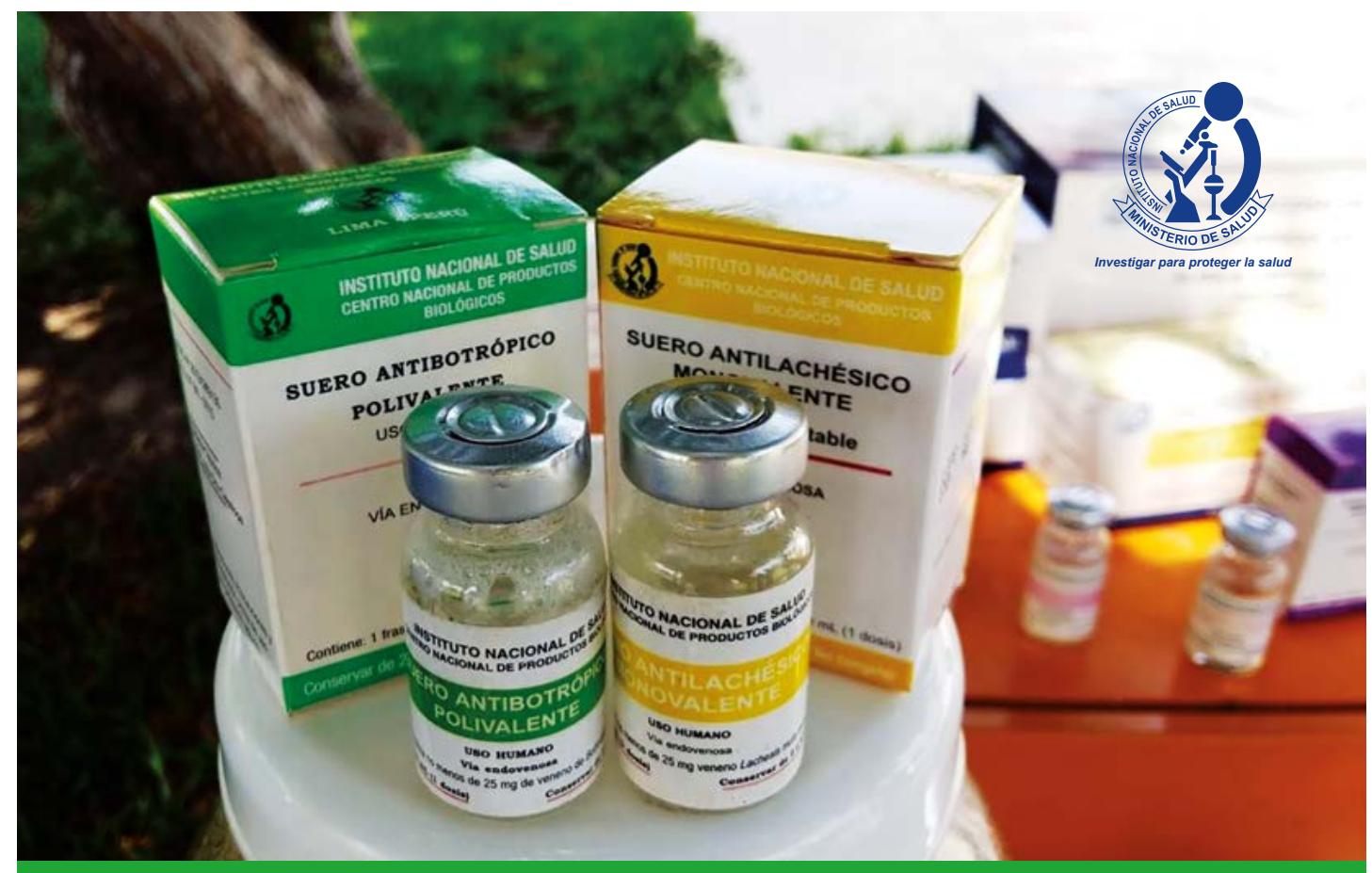

Sueros producidos por el INS, para contrarrestar accidentes por animales ponzoñosos: Serpientes y arañas 